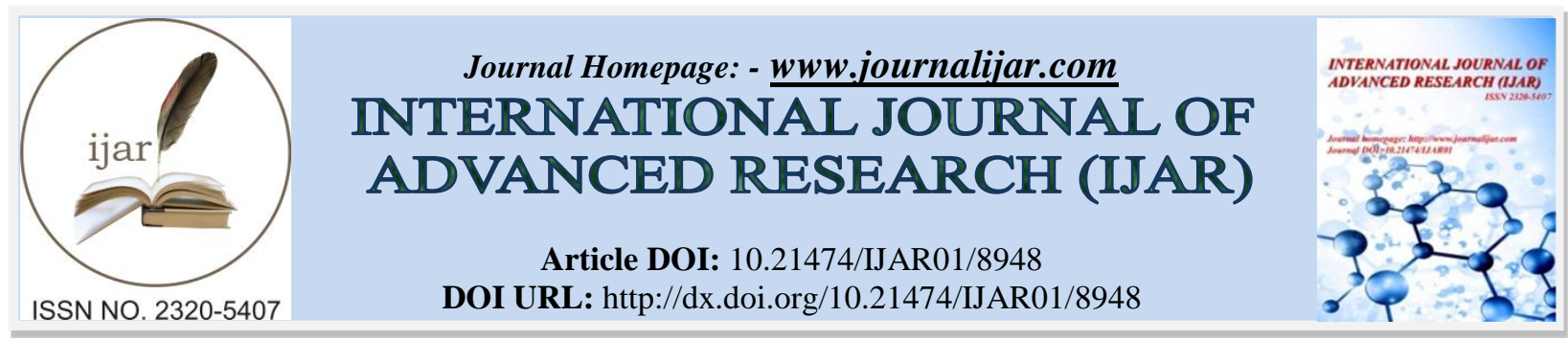

RESEARCH ARTICLE

\title{
EFFECT OF KARELA ON THE PHARMACODYNAMICS OF PIOGLITAZONE IN NORMAL AND ALLOXAN INDUCED DIABETIC RATS.
}

Rajasekhara Reddy $\mathbf{T}^{1}$, Swathi $\mathbf{P}^{2}$ and Eswar Kumar $\mathbf{K}^{2}$.

1. Clinwave Research Private Limited, Kukatpally, Hyderabad.

2. A.U.College of Pharmaceutical Sciences, Andhra University, Visakhapatnam.

\section{Manuscript Info}

Manuscript History

Received: 22 February 2019

Final Accepted: 24 March 2019

Published: April 2019

Key words:-

Pioglitazone, Karela, Blood Glucose.

\begin{abstract}
Karela is a common name of Momordica charantia. The present study was carried out to study the herb drug interactions between the traditional medicine Karela with Thiazolindinediones, Pioglitazone in normal and diabetic conditions. Blood samples were collected from rats by retro orbital puncture at regular intervals of time $0,1,2,3,4,6,8$, $10,12 \mathrm{hr}$ of rats treated with Pioglitazone 5, 10 and $20 \mathrm{mg} / \mathrm{kg}$ bd.wt and Momordica charantia 100 and $200 \mathrm{mg} / \mathrm{kg}$ bd.wt. The Pioglitazone and Karela showed dose dependent reduction of blood glucose levels. The optimum blood glucose reduction was obtained at $10 \mathrm{mg} / \mathrm{kg}$ of pioglitazone and $200 \mathrm{mg} / \mathrm{kg}$ of Karela in normal rats. The blood glucose levels were found to be decreased with corresponding elevated insulin levels in both single and multiple dose combinations of Pioglitazone and Karela in normal rats (4hr) as well as in alloxan induced diabetic rats (4hr) compared with the pioglitazone alone. Since the combination of Karela and pioglitazone produced severe hypoglycemia in combined treatment due to pharmacodynamic interactions, care must be taken while prescribing the combination in clinical situation.
\end{abstract}

Copy Right, IJAR, 2019,. All rights reserved.

\section{Introduction:-}

Herbal medicines are popular used preventive remedies for many diseases and play a key role in the human health care of a vast majority of world's population. From last five thousand years human being has relied on natural product as the primary source of medicines. However, the last two centuries have brought an explosion to understand how the natural products are produced and how they react with other organisms. The World Health Organization (WHO) estimates that $80 \%$ of the world health populations presently use herbal medicines for some aspect of primary health care [1]. Millions of people now a day's use herbal medicines along with prescription and non-prescription medications that the natural agents are safer than the conventional synthetic chemo therapeutic agents [2].

The herbs are alternative treatment option apart from the convention drug therapy is now day practice in patients with diabetes and other associated complications. Polypharmacy is a common phenomenon in the type 2 diabetes. The most commonly used alternatives are herbs and herbal formulations. But they initiate many herb drug interactions without any previous reports. Even the monographs of existed drugs had data regarding the drug-drug interactions but not about herb-drug interactions [3]. The drug interaction may be either pharmacokinetic or pharmacodynamic interactions at the one dose or at another dose of toxic lead to either agonistic or antagonistic 
reactions tends to in effectiveness of intended drug or enhanced pharmacological actions. Research need to explore the unexplored drug interactions of combined use of herb drugs for therapeutic outcomes. Based on the research outcomes, it needs to adjust the dosage regimen and individualization.

Diabetes is a metabolic disease, where there is a chance of concomitant administration of many herbs with oral hypoglycemic agents. There is a possibility of herb-drug interactions in terms of pharmacokinetic and pharmacodynamic interactions which affecting safety and efficacy of the prescribed medicines in diabetic condition. Antidiabetic drugs have been found to potential interactions with co-administered herbs due to CYP enzymes. Some of the examples are pioglitazone, repaglinide, and rosiglitazone acts substrates for CYP2C8; glibenclamide, glimepiride, glipizide, nateglinide, and rosiglitazone for CYP2C9; pioglitazone and repaglinide for CYP3A4 [4]. Pioglitazone is metabolized by CYP 2C8 and CYP3A4 microsomal liver enzymes [5]. Herbal medicines that modulate intestinal and hepatic CYPs can alter the bioavailability and clearance of co-administered drugs. Example Moringa oleifera with simultaneous administration of Pioglitazone potentiate the activity of pioglitazone by decreasing the metabolism of pioglitazone as a result of inhibition CYP3A4 [6]. Momordica charantia, commonly called as Karela used as herbal remedy for diabetes. People are used as home remedy as well as available in herbal drug and in many herbal formulation marketed by popular companies such as Himalaya, Patangali, Herbal Hills, Healing herbs, Panchaveda, Morpheme, Dr. Wakede's, Sri Sri, Vedic etc. Hence, there is chance of co administration of widely prescribe Pioglitazone with Karela. The present study was planned to conduct the pharmacodynamic interactions between the Pioglitazone and Momordica charantia in normal and diabetic rats.

\section{Materials and Methods:-}

Animals:

Albino rats of either sex obtained from M/s. Mahaveer Enterprises, All animals were maintained on pellet diet supplied by M/s. Rayan Biotechnologies Pvt. Ltd., Hyderabad with 12h/12h light/dark cycle and water ad libitum. Animals were fasted for $18 \mathrm{~h}$ before the experiment. The Momordica charantia obtained from Laila impex Pvt Ltd., Vijayawada as gift sample.

\section{Study in normal rats}

A group of six albino rats weighing between 250-300 g were administered with 5, 10 and $20 \mathrm{mg} / \mathrm{kg}$ body weight Pioglitazone, orally. The same group was administered with 100 and $200 \mathrm{mg} / \mathrm{kg}$ body weight Momordica charantia, orally after a wash out period of one week. The same group was also administered with $200 \mathrm{mg} / \mathrm{kg}$ body weight Momordica charantia $30 \mathrm{~min}$ prior to $10 \mathrm{mg} / \mathrm{kg}$ body weight Pioglitazone, after a further wash out period of 1 week. Blood samples were withdrawn from retro orbital puncture at $0,1,2,4,6,8,10$, and $12 \mathrm{~h}$ intervals. Blood samples were analyzed for blood glucose levels by GOD/POD method [7] using commercial glucose kits (Span diagnostics) insulin levels were estimated by using ELISA kits.

\section{Study in diabetic rats}

Diabetes was induced by the administration of alloxan monohydrate in two doses $100 \mathrm{mg}$ and $50 \mathrm{mg} / \mathrm{kg}$ body weight intraperitoneal for two consecutive days [8]. A group of 6 rats with blood glucose levels above $250 \mathrm{mg} / \mathrm{dL}$ was selected for the study. The study similar to the one conducted in normal rats was repeated in diabetic group.

Data and Statistical Analysis: Data was expressed as mean \pm standard error of mean (SEM). The significance was determined by Two way ANOVA, Bonferroni post test.

\section{Results \&Discussion:-}

Induction of CYP enzyme can lower the plasma concentration of concurrently administered drugs and leads to reduced therapeutic benefit. To assess the interaction between the Pioglitazone and Karela (Momordica charantia), the study was designed to indentify the pharmacodynamic interactions in both normal and in alloxan induced diabetic rats. Pioglitazone at 5, 10 and $20 \mathrm{mg} / \mathrm{kg}$ bd.et and aqueous fruit extracts of Momordica charantia (AQMC) at 100,200 and $300 \mathrm{mg} / \mathrm{kg}$ bd.wt were selected in this study to identify the dose dependent blood glucose reduction. 
Figure 1:-Comparison of \% blood glucose reduction of Pioglitazone $5 \mathrm{mg} / \mathrm{kg}, 10 \mathrm{mg} / \mathrm{kg}$ and $20 \mathrm{mg} / \mathrm{kg}$.

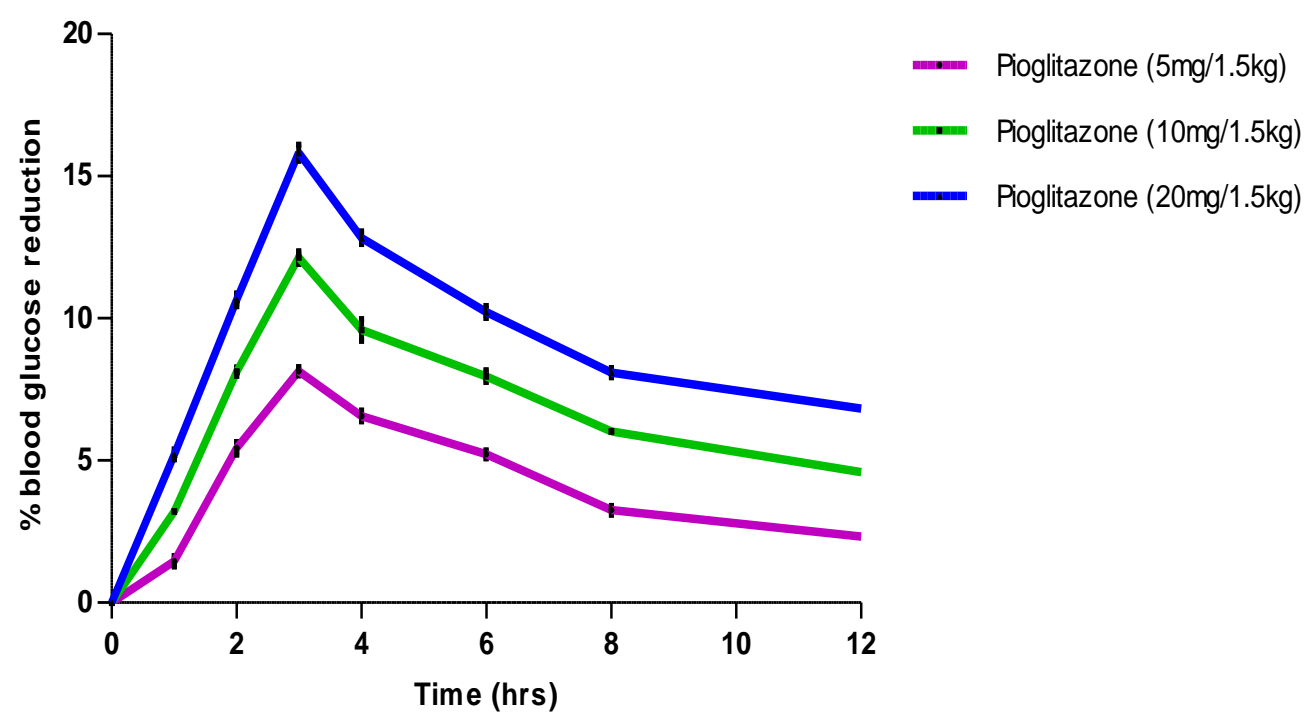

Figure 2:-Comparison of \% blood glucose reduction of AEMC $(100 \mathrm{mg} / \mathrm{kg}, 200 \mathrm{mg} / \mathrm{kg}$ and $300 \mathrm{mg} / \mathrm{kg})$.

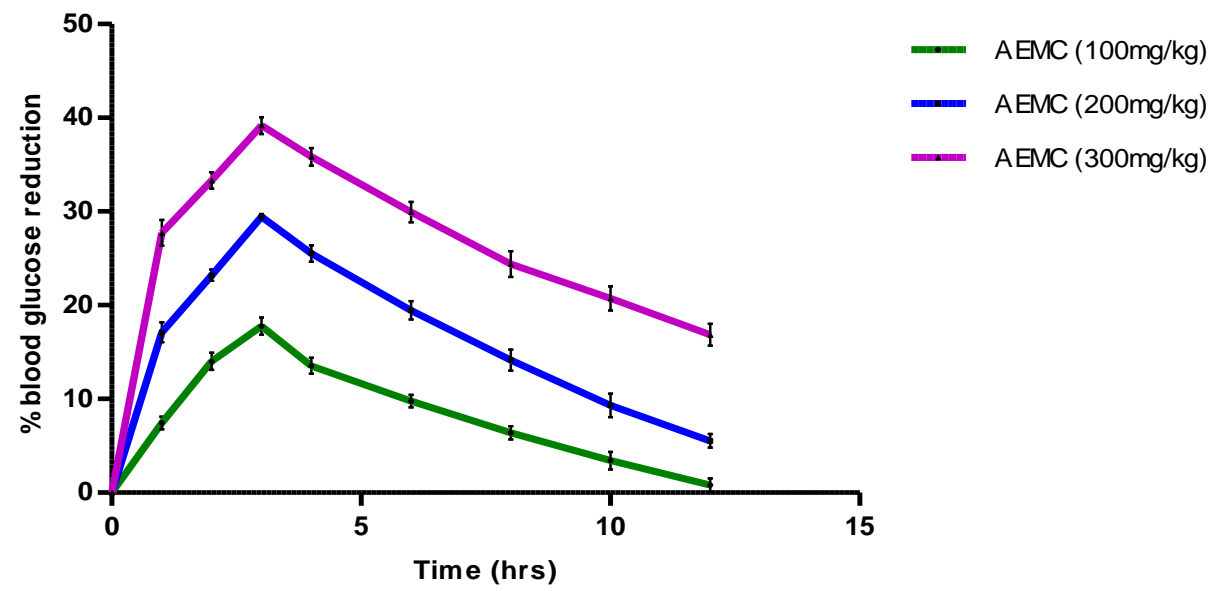

Figure 3:-Comparison of \% blood glucose reduction of Pioglitazone $10 \mathrm{mg} / \mathrm{kg}$, AEMC (200mg/kg) and single and multiple dose Combinations in normal rats

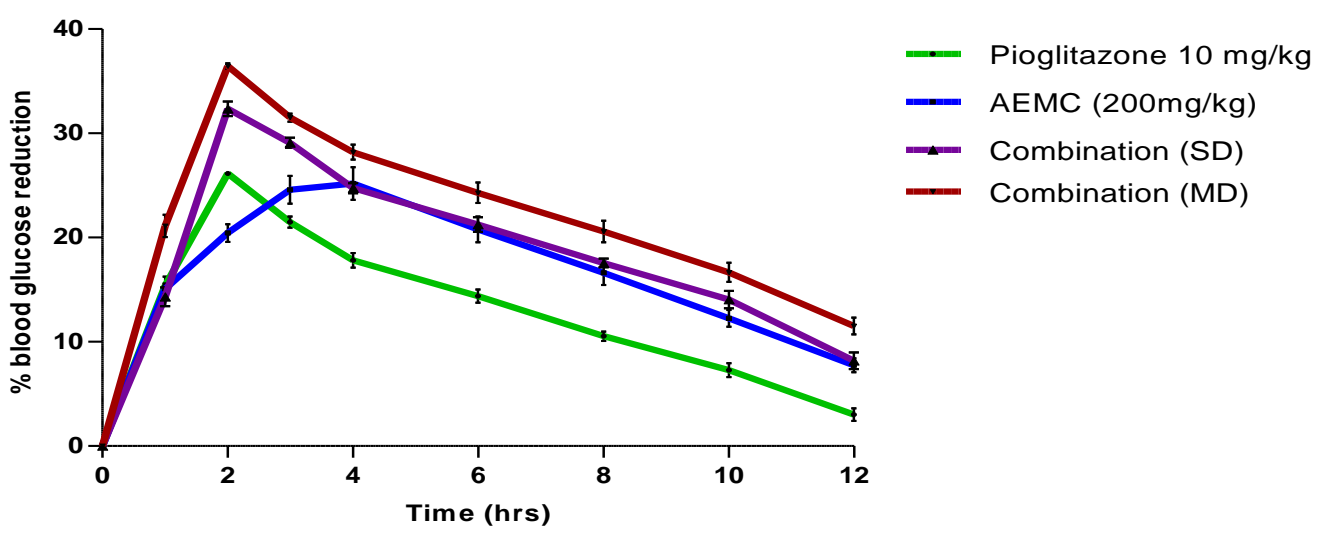


Table 1:-Mean Serum insulin $(\mu \mathrm{IU} / \mathrm{mL})$ with mean serum glucose level $(\mathrm{mg} / \mathrm{dL})$ in Pioglitazone, AEMC and single and multiple dose treatment AEMC +Pioglitazone:

\begin{tabular}{|l|l|l|l|}
\hline Groups & Time $(\mathbf{h r s})$ & $\begin{array}{l}\text { Mean serum glucose } \\
\text { levels }(\mathbf{m g} / \mathbf{d L})\end{array}$ & Serum Insulin $(\boldsymbol{\mu I U} / \mathbf{m L})$ \\
\hline \multirow{2}{*}{ Pioglitazone } & $0 \mathrm{hr}$ & $82.17 \pm 1.64$ & $9.47 \pm 0.11$ \\
\cline { 2 - 4 } & $2 \mathrm{hr}$ & $60.33 \pm 1.29$ & $11.39 \pm 0.09$ \\
\hline AEMC & $3 \mathrm{hr}$ & $57.83 \pm 1.53$ & $12.13 \pm 0.05$ \\
\hline AEMC + Pioglitazone (SD) & $4 \mathrm{hr}$ & $56.17 \pm 1.25$ & $12.17 \pm 0.05$ \\
\hline AEMC + Pioglitazone (MD) & $4 \mathrm{hr}$ & $52.17 \pm 1.31$ & $13.30 \pm 0.04$ \\
\hline
\end{tabular}

Figure 4:-Comparison of \% blood glucose reduction of Pioglitazone $10 \mathrm{mg} / \mathrm{kg}$, AEMC (200mg/kg) and single and multiple dose Combinations in Diabetic rats

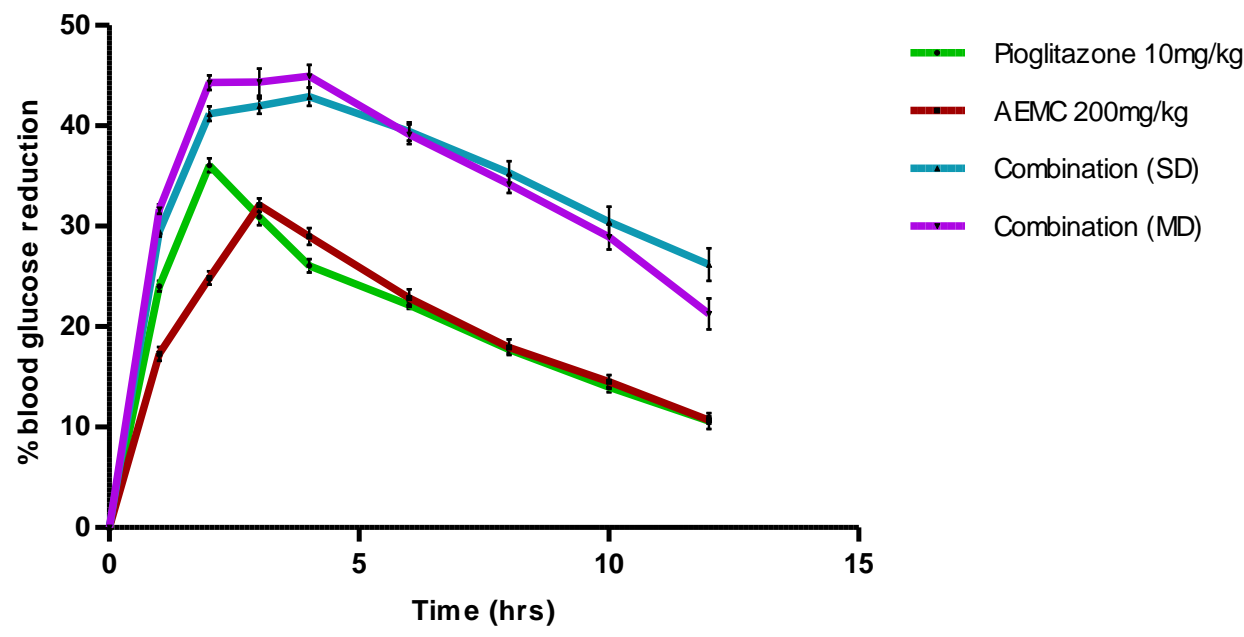

Table 2:-Mean Serum insulin ( $\mu \mathrm{IU} / \mathrm{mL})$ with mean serum glucose level $(\mathrm{mg} / \mathrm{dL})$ in Pioglitazone, AEMC and single and multiple dose treatment AEMC +Pioglitazone

\begin{tabular}{|l|l|l|l|}
\hline Groups & Time (hrs) & $\begin{array}{l}\text { Mean serum glucose } \\
\text { levels }(\mathbf{m g} / \mathbf{d L})\end{array}$ & Serum Insulin $(\boldsymbol{\mu I U} / \mathbf{m L})$ \\
\hline Pioglitazone & $0 \mathrm{hr}$ & 262.336 .59 & $6.33 \pm 0.03$ \\
\cline { 2 - 4 } & $2 \mathrm{hr}$ & 167.674 .61 & $7.25 \pm 0.01$ \\
\hline AEMC & $3 \mathrm{hr}$ & 186.832 .96 & $7.07 \pm 0.03$ \\
\hline AEMC + Pioglitazone (SD) & $4 \mathrm{hr}$ & 148.334 .57 & $7.72 \pm 0.02$ \\
\hline AEMC + Pioglitazone (MD) & $4 \mathrm{hr}$ & 143.005 .47 & $7.79 \pm 0.02$ \\
\hline
\end{tabular}

In normal rats, Pioglitazone and AEMC when administered alone produced significant decrease in blood glucose level in a dose dependent manner. A dose of $10 \mathrm{mg} / \mathrm{kg}$ of Pioglitazone and $200 \mathrm{mg} / \mathrm{kg}$ of AQMC bd.wt found to have optimal reduction in blood glucose levels (about 30\%) as shown in graph 1 and 2 . The insulin levels were found to be enhanced at peak reduction of blood glucose with AEMC at $3 \mathrm{hr}$ compared to $0 \mathrm{hr}$ (table 1). In combination, the selected dose of AEMC found to enhance the hypoglycemic activity produced by Pioglitazone with single dose and as well as multiple dose treatments also. The insulin levels at peak reduction in blood glucose levels were also found to be altered with single and multiple dose treatments (graph 3). This indicates there is an existence of pharmacodynamic interaction between AEMC and Pioglitazone in normal rats. A dose of $200 \mathrm{mg} / \mathrm{kg}$ bd.wt found to have $32 \%$ reduction in blood glucose levels. The insulin levels were found to be enhanced slightly at peak reduction of blood glucose with AEMC at $3 \mathrm{hr}$ compared to 0hr. The alloxan used to induce diabetes in the present study.

Alloxane is commonly used diabetes inducing agent. It works by inducing the sudden release of insulin from pancreatic $\beta$ cells. The islet response to glucose even when high concentrations of glucose were used [9]. Further, the alloxan action in the pancreas is preceded by its rapid uptake by pancreatic beta cells that have been proposed to 
be one of the important features determining alloxan diabetogenicity. In combination, the selected dose of AEMC found to enhance the antihyperglycemic activity produced by Pioglitazone with single dose and multiple dose treatments in diabetic rats (graph 4). The insulin levels at peak reduction in blood glucose levels were also found to be altered with single and multiple dose treatments. This indicates there is an existence of pharmacodynamic interaction between AEMC and Pioglitazone in diabetic rats. The Pharmacodynamic interaction may be due to their synergistic antihyperglycemic effect or due to inhibition of metabolism of Pioglitazone as Momordica charantia reported to have inhibitory activity on CYP 3A4 and CYP 2C19 [10].

The same results were also found in the studies conducted Simone B., 2012 [11]., Momordica charantia reported to have inhibitory activity against the CYP 1A1, CYP2C19 and CYP3A4 I in invitro. Lal VK., 2011 reported that Momordica charantia shows synergistic effect with glibenclamide [12] and metformin [13] by elevating the blood glucose levels. Nivitabishekam SN., 2009 also reported that the Momordica charantia potentiates the hypoglycemic effect of Rosiglitazone in both normal and STZ induced diabetes [14]. The same might be responsible for synergistic hypoglycemic and antihyperglycemic activity of Pioglitazone with Karela.

\section{Conclusions:-}

The combinations are not safe in rats; care must be taken when they are administered with pioglitazone to avoid severe hypoglycemia. The herbal drug manufacturers also need to provide the information regarding the potent and possible herb drug interactions of used herbs.

\section{References:-}

1. Shaheena M, Jan Barnsley, and Raisa B. Deber. Accountability and primary healthcare. Healthc Policy. 2014; 10(SP): 90-98.

2. Sandhya W. Global health care challenge: Indian experiences and new prescriptions. E J Biotech, 2004; 7: 217223.

3. Berman AF. Herb-drug interactions, The Lancet. 2000;355:134-8.

4. Anthony, J.B., and C.M. Gregory. Pharmacology Weekly. Retrieved June 2014, from http://www.pharmacologyweekly.com/content/pages/cytochrome-cyp-p450-enzyme medication herbssubstrates.

5. Deng LJ, Wang F, Li HD. Effect of gemfibrozil on the pharmacokinetics of pioglitazone. Eur J Clin Pharmacol, 2005; 61: 831-836

6. Bharathi K, Sandhya M and KVSRG Prasad. Effect of Moringa oleifera on the Pharmacokinetics and Pharmacodynamics of Pioglitazone, The FASEB Journal, 2017;31(1): 822.5

7. Trinder P, Determination of blood glucose using an oxidaase-peroxidase system with a non carcinogenic chemogen. J Clin Pathol., 1961; 22: 158-161.

8. Kala MJ, Tresina PS, Mohan VR. Antioxidant, antihyperlipidaemic and antidiabetic activity of Eugenia floccosa bedd leaves in alloxan induced diabetic rats. J Basic Clin Pharm. 2012;3:235-40.

9. Kliber A, Szkudelski T, Chichlowska J. Alloxan stimulation and subsequent inhibition of insulin release from in situ perfused rat pancreas. J Physiol Pharmacol 1996;47:321-8

10. Pranja AS, Philip Eck and Pratibha V Nerurkar. Modulation of Human Cytochrome P450 by Momordica charantia (Bitter Melon). The FASEB Journal, 2009; 23(1): 688.5.

11. Simone B, Mario S and Rupika D. Cytochrome P450 Enzyme Inhibitors from Nature, Enzyme Inhibition and Bioapplications, Prof. Rakesh Sharma (Ed.),2012; ISBN: 978-953-51-0585-5

12. Lal VK, Gupta PP, Tripathi P, Pandey A. Iteraction of Momordica charatia fruit juice with glibeclamide in streptozotocin induced diabetic rats. Pharmacologyonline, 2011; 3: 853-857.

13. Tripathi P, Gupta PP and Vijay Kumar. Interaction of Momordica charantia with Metformin in Diabetic Rats, American Journal of Pharmacology and Toxicology, 2013, 8 (3): 102-106

14. Nivitabishekam SN, Asad M, Prasad VS. Pharmacodynamic interaction of Momordica charantia with rosiglitazone in rats. Chem Biol Interact. 2009 12;177(3):247-53. 